\title{
MINAT SISWA DALAM MENGIKUTI EKSTRAKURIKULER FUTSAL DI SMA NEGERI SE KECAMATAN CIKAMPEK
}

\author{
Albert Paulus Situmeang ${ }^{1}$, Fahrudin ${ }^{2}$, Rahmat Iqbal ${ }^{3}$ \\ Universitas Singaperbangsa Karawang ${ }^{123}$ \\ albertpaulussitumeang@gmail.com ${ }^{1}$, arrufahrudin@gmail.com ${ }^{2}$, amaiq.4@gmail.com ${ }^{3}$
}

\begin{abstract}
ABSTRAK
Penelitian ini dilarbelakangi oleh rendahnya minat siswa dalam mengikuti ekstrakurikuler futsal di SMA Negeri Sekecamatan Cikampek. Penelitian ini bertujuan untuk mengetahui seberapa besar tingkat minat Siswa-Siswi Dalam mengikuti Ekstrakurikuler Futsal Di SMA Negeri Sekecamatan Cikampek. Penelitian ini merupakan penelitian deskriptif kuantitatif, metode yang digunakan adalah survey. Teknik pengumpulan data berupa angket menggunakan tes skala likert. Populasi yang digunakan adalah siswa siswi yang mengikuti ekstrakurikuler futsal di SMA Negeri se Kecamatan Cikampek yang berjumlah 125 siswa. Sampel yang digunakan dalam penelitian ini sebanyak 55 siswa dengan teknik pengambilan sampel yaitu simple random sampling. Data pada penelitian dianalisis dengan menggunakan statistik deskriptif dengan presentase.Hasil penelitian menunjukan tingkat minat siswa siswi dalam mengikuti ekstrakurikuler futsal di SMA Negeri Se Kecamatan Cikampek secara keseluruhan berada pada kategori "Kurang Baik" dengan jumlah 24 siswa dan presentase sebesar (44\%).
\end{abstract}

Kata Kunci: Minat Siswa; Ekstrakurikuler; Futsal.

\section{ABSTRACT}

This research was motivated by the low interest of students in participating in futsal extracurricular activities at SMA Negeri Sekecamat Cikampek. This study aims to determine the level of interest of the students in participating in the Futsal Extracurricular at SMA Negeri Sekec Kecamatan Cikampek. This research is a descriptive quantitative research, the method used is survey. The data collection technique was a questionnaire using a Likert scale test. The population used was 125 students who took futsal extracurricular activities in SMA Negeri Cikampek. The sample used in this study were 55 students with a sampling technique that is simple random sampling. The data in the study were analyzed using descriptive statistics with percentages. The results showed the level of interest of students in participating in futsal extracurricular activities at SMA Negeri Se Cikampek District as a whole was in the "Not Good" category with a total of 24 students and a percentage of $(44 \%)$.

Keywords: Student Interests; Extracurricular; Futsal.

Dipublikasikan Oleh :

UPT Publikasi dan Pengelolaan Jurnal

Universitas Islam Kalimantan Muhammad Arsyad Al-Banjari Banjarmasin 


\section{PENDAHULUAN}

Andriani \& Rasto, (2019) mengemukakan bahwa arti kata minat yaitu kecenderungan hati yang tinggi terhadap sesuatu, gairah atau keinginan. Hal ini diperkuat oleh Vinet \& Zhedanov, (2011) minat adalah rasa lebih suka dan rasa keterikatan pada suatu hal atau aktivitas, tanpa ada yang menyuruh. Lalu penelitian oleh Charisma Nur \& Cahyo, (2017) Minat dapat diartikan sebagai suatu kondisi yang terjadi apabila seseorang melihat ciri-ciri situasi yang dihubungkan dengan keinginan-keinginan atau kebutuhan-kebutuhannya sendiri. Selain itu penelitian oleh Armi, (2015) minat merupakan penerimaan akan suatu hubungan antara diri sendiri dengan sesuatu diluar diri semakin kuat atau dekat dengan hubungan tersebut, semakin besar minat seseorang. minat dapat diartikan sebagai suatu kesukaan, kegemaran atau kesenangan akan sesuatu (Martaningtyas, 2019) sedangkan penelitian oleh Halim, (2013) yang mengemukakan bahwa minat merupakan dorongan dalam diri seseorang atau faktor yang menimbulkan ketertarikan atau perhatian secara efektif, yang menyebabkan dipilihnya suatu objek atau kegiatan yang menguntungkan, menyenangkan, dan lama kelamaan akan mendatangkan kepuasan dalam dirinya. Sehingga dapat disimpulkan bahwa bahwa minat adalah kecenderungan jiwa (perasaan suka) seseorang terhadap sesuatu hal yang menyebabkan dirinya mau untuk melakukan sesuatu dengan senang hati dan tanpa ada paksaan.

Minat sangatlah penting dalam proses pembelajaran, karena minat merupakan salah satu faktor yang mempengaruhi keberhasilan atau ketercapaian tujuan pembelajaran (Budiono, 2013). Oleh karena itu sebelum pembelajaran dimulai guru harus berupaya membangkitkan minat siswa-siswi untuk belajar, sehingga materi yang disampaikan dapat diterima dengan baik oleh siswa-siswi. Safitri \& Kustini, (2014) menyubutkan ciri ciri siswa yang memiliki minat antara lain: 1) Perasaan senang, 2) Keterlibatan Siswa. Secara garis besar ada 2 faktor yang dapat mempengaruhi minat yaitu, faktor yang berasal dari dalam diri (internal) dan yang bersumber dari luar individu (eksternal) tersebut (Rohmantunisa, 2020).

Ekstrakurikuler adalah kegiatan yang diselenggarakan di luar jam pelajaran yang tercantum dalam susunan program sesuai dengan keadaan dan kebutuhan sekolah (Pramana, 2019). Dan diperkuat oleh penelitian Dollah, (2018) . Kegiatan ekstrakurikuler sebagai wadah dalam menampung bakat dan minat yang dimiliki siswa-siswi ini harus disesuaikan dengan kemampuan sekolah dalam menyelenggarakan kegiatan tersebut guna mencapai apa yang diinginkan. Adapun sasaran dari kegiatan ekstrakurikuler adalah bidang kesehatan, keterampilan, sosial maupun rekreasi. Sehingga dapat disimpulkan bahwa Kegiatan ekstrakurikuler merupakan kegiatan yang dilakukan diluar jam biasa termasuk pada hari libur, dengan maksud untuk memperluas wawasan, mendorong pembinaan sikap atau nilai, dan memungkinkan lebih lanjut berbagai mata pelajaran yang dipelajari.

Futsal adalah permainan bola yang dimainkan oleh dua tim, yang masing-masing tim beranggotakan lima orang dengan tujuan untuk memasukkan bola ke gawang lawan, dengan manipulasi bola dan kaki (Widiyono, 2020). Serta penelitian oleh Prakoso, (2013) yang mengemukakan bahwa futsal adalah salah satu cabang olahraga yang model permainannya dimodifikasi dari olahraga sepakbola. Berbeda dengan sepakbola, futsal ini hanya dimainkan oleh beberapa orang saja dan di tempat atau lapangan yang relatif kecil daripada olahraga sepakbola. Permainan futsal lebih banyak dimainkan oleh anak-anak remaja hingga dewasa. Hal ini terbukti dengan banyaknya klub futsal di setiap daerah dan pertandingan-pertandingan futsal baik yang diselenggarakan secara lokal, regional, nasional, maupun internasional (Halim, 2013).

Seorang anak (siswa-siswi) yang melakukan aktivitas olahraga disertai minat yang tinggi dalam dirinya akan membuat siswa-siswi dalam melakukan aktivitas itu dengan sungguh-sungguh dan hasilnya akan lebih memuaskan atau hasilnya akan lebih baik, sebab sebelum melakukan aktifitas olahraga, siswa-siswi tersebut memiliki tujuan yang ingin dicapai. Dengan tujuan itulah siswa-siswi akan berusaha melakukan hal yang terbaik guna mencapai apa yang diinginkan. Untuk mencapai tujuan yang diinginkan siswa-siswi, dipengaruhi oleh faktor dari dalam dan luar siswa-siswi. Faktor dari dalam antara lain: sikap toleransi, sikap mau bekerja sama, sikap percaya pada teman, sikap percaya diri, sikap disiplin, dan sikap ingin berprestasi. Sedangkan faktor dari luar antara lain, persetujuan dari orang tua, sarana dan prasarana, dan media. Oleh karena itu kebutuhan dan tujuan seseorang dalam melakukan suatu aktivitas itu berbeda-beda dan kedua faktor tersebut itu memiliki peranan yang sama.

Berdasarkan fakta yang saya amati dari beberapa Sekolah Menengah Atas yang ada di Kecamatan Cikampek, banyak siswa yang tertarik untuk mengikuti ekstrakurikuler futsal, hal ini tentunya didasari oleh beberapa faktor yang mempengaruhi minat siswa dalam mengikuti kegiatan ekstrakurikuler futsal. Untuk dapat melaksanakan proses kegiatan ekstrakurikuler futsal dengan baik dan benar, seorang guru atau pelatih sebaiknya mengetahui kemampuan awal siswa, dengan demikian para siswa dapat dikelompokkan sesuai dengan kemampuan dan jenis olahraga yang diminati. Sehingga kegiatan ekstrakurikuler futsal dapat berjalan dengan baik dikarenakan siswa telah tepat dalam memilih jenis olahraga yang mereka minati

Siswa yang mempunyai anggapan positif ataupun baik tentang sesuatu obyek( Ekstrakurikuler futsal) hingga dia hendak mempunyai motivasi yang positif ataupun baik, namun apabila orang mempunyai anggapan

Dipublikasikan Oleh : 
yang negatif ataupun kurang baik tentang sesuatu obyek hingga dia hendak mempunyai motivasi belajar yang kurang baik. Ini meyakinkan kalau minat siswa terhadap ekstrakurikuler futsal sangat mempengaruhi terhadap pencapaian keberhasilan ekstrakurikuler itu sendiri. Hal itu dapat dibuktikan melalui penelitian terdahulu oleh Romadon, (2018) tentang "Survei minat siswa dalam mengikuti ekstrakurikuler futsal di SMA Negeri se Kecamatan Kibin" mengemukakan bahwa minat siswa dalam mengikuti ekstrakurikuler futsal di SMA Negeri se Kecamatan Kibin yang masuk kategori sangat tinggi sebesar 12,46\%, pada kategori tinggi sebesar $10 \%$, pada kategori rendah sebesar 59,22\%, dan kategori sangat rendah 18,32\%. Hal tersebut diartikan minat siswa dalam mengikuti ekstrakurikuler futsal di SMA Negeri se Kecamatan Kibin adalah rendah. Oleh sebab itu pengamat terdahulu mengajukan sebagai anjuran antara lain. 1) Pihak sekolah sebaiknya dapat meningkatkan minat siswa dengan senangtiasa menyediakan sarana dan prasarana yang digunakan dalam kegiatan ekstrakurikuler. 2) Pelatih dan pembina ekstrakurikuler futsal dapat memberikan motivasi yang lebih untuk meningkatkan minat siswa. 3) Siswa sebaiknya menyadari manfaat dari pembinaan ekstrakurikuler futsal yang dilakukan, sehingga dapat meningkatnya minat siswa. Berangkat dari hal tersebut penelitian ini bertujuan untuk mengetahui minat siswa-siswi dalam mengikuti ekstrakurikuler futsal di SMA Negeri se Kecamatan Cikampek.

\section{METODE}

Penelitian ini menggunakan metode deskriptif dengan pendekatan kuantitatif melalui penggunaan instrumen survey study, dengan teknik pengumpulan data berupa angket menggunakan tes skala likert. untuk mengetahui minat siswa dalam mengikuti ekstrakurikuler futsal di SMA Negeri se Kecamatan Cikampek. Metode riset kuantitatif dimaksud bagaikan tata cara riset yang berlandaskan pada filsafat positivisme, yang digunakan buat mempelajari pada populasi ataupun ilustrasi tertentu (Sugiyono, 2013). Berikut ini merupakan kisi-kisi instrumen penelitian dari variabel minat siswa dalam mengikuti ekstrakurikuler futsal yang nantinya akan dijadikan pada penyusunan instrumen penelitian.

Tabel 1. Kisi-Kisi Instrumen Mnat Siswa Dalam Mengikuti Ekstrakurikuler Futsal

\begin{tabular}{|c|c|c|c|c|c|}
\hline \multirow[t]{2}{*}{ VARIABEL } & \multirow[t]{2}{*}{ DIMENSI } & \multirow[t]{2}{*}{ INDIKATOR } & \multicolumn{2}{|c|}{$\begin{array}{c}\text { BUTIRAN } \\
\text { PERNYATAAN }\end{array}$} & \multirow[t]{2}{*}{$\begin{array}{l}\text { JUMLAH } \\
\text { SOAL }\end{array}$} \\
\hline & & & $(+)$ & $(-)$ & \\
\hline \multirow{8}{*}{$\begin{array}{c}\text { Minat Siswa Siswi } \\
\text { Dalam Mengikuti } \\
\text { Ekstrakurikuler Futsal } \\
\text { di SMA Negeri se } \\
\text { Kecamatan Cikampek }\end{array}$} & \multirow[t]{4}{*}{ Internal } & Motivasi & $1,3,5,6,8$ & $2,4,7$ & 7 \\
\hline & & Cita - Cita & $9,10,12,13$ & 11 & 5 \\
\hline & & Bakat & $14,15,16,18$ & 17 & 5 \\
\hline & & Hobi & $\begin{array}{c}19,21,23,24, \\
25\end{array}$ & 20,22 & 7 \\
\hline & \multirow[t]{4}{*}{ Eksternal } & Keluarga & $\begin{array}{c}26,27,28,29, \\
30,31\end{array}$ & 29 & 7 \\
\hline & & Teman Pergaulan & $\begin{array}{c}32,34,35,36, \\
37,38\end{array}$ & 33 & 7 \\
\hline & & Lingkungan & $39,41,43$ & 40,42 & 5 \\
\hline & & Fasilitas & $44,45,46,48$ & $47,49,50$ & 7 \\
\hline \multicolumn{2}{|c|}{ Jumlah } & & 36 & 14 & 50 \\
\hline
\end{tabular}

Minat siswa dalam mengikuti ekstrakurikuler futsal dipengaruhi oleh 2 faktor, yaitu: 1) faktor internal yang terdiri dari Motivasi, Cita-Cita, Bakat, Hobi. Dan 2) Faktor Eksternal yang meliputi Keluarga, Teman Pergaulan, Lingkungan, Fasilitas. Terdapat 50 butir pernyataan yang terbagi menjadi 36 butir positif dan 14 butir negatif. Sebelum angket digunakan, maka diperlukan uji instrumen uji validitas untuk mengukur ketepatan disetiap butir soal, digunakan teknik produk momen sari karl pearson dengan taraf signifikansi $5 \%$. Butir soal dikatakan valid apabila $r_{\text {hitung }}>r_{\text {tabel }}$, untuk nilai $r_{\text {tabel }}$ dengan responden 15 orang adalah sebesar 0,514. Setelah dilakukan perhitungan dapat diketahui terdapat 9 butir soal yang tidak valid yaitu butir soal nomor $6,7,19,21,35,37,42,47$ dan 49. Jadi peneliti hanya memakai 41 butir soal dari total 50 butir soal, Dan dilakukan uji reabilitas dengan menggunakan rumus alpha cronbach dengan taraf signifikansi 5\%, suatu instrumen dikatakan reliable jika $r_{11}>r_{\text {tabel }}$, hasil uji reabilitas diperoleh nilai $r_{11}=0,877>r_{\text {tabel }}=0,60$ dengan demikian menunjukan angket yang diuji cobakan reliable dan dapat digunakan untuk pengumpulan data penelitian.

Adapun Desain dalam penelitian ini menggunakan langkah langkah penelitian kuantitatif deskriptif terdiri dari: 1.) Mengenali terdapatnya kasus yang signifikan buat dipecahkan lewat tata cara deskriptif, 2.)

Dipublikasikan Oleh :

UPT Publikasi dan Pengelolaan Jurnal

Universitas Islam Kalimantan Muhammad Arsyad Al-Banjari Banjarmasin 
Menghalangi serta merumuskan kasus secara jelas, 3.) Memastikan tujuan serta khasiat riset, 4.) Melaksanakan riset pustaka yang berkaitan dengan kasus, 5.) Memastikan kerangka berpikir, serta persoalan riset serta ataupun hipotesis riset, 6.) Mendesain tata cara riset yang hendak digunakan tercantum dalam perihal ini memastikan populasi, ilustrasi, metode sampling, memastikan instrumen, mengumpulkan informasi, serta menganalisis informasi, 7.) Mengumpulkan, mengorganisasikan, serta menganalisis informasi dengan memakai metode statistika yang relevan, serta 8.) Membuat laporan riset. (Gunawan, 2020)

Populasi dalam penelitian ini adalah seluruh siswa-siswi yang mengikuti ekstrakurikuler futsal di SMA Negeri se Kecamatan Cikampek yang berjumlah 125 siswa. Dan penentuan jumlah sampel menurut (Sugiyono, 2013) mengenai nonprobability sampling dengan menggunakan teknik sampling jenuh sehingga sampel yang digunakan dalam penelitian ini adalah 97 responden sesuai dengan populasi dalam penelitian. Dalam perhitungan statistik menggunakan bantuan aplikasi microsoft excel 2013. Berikut ini merupaka skala pengskoran (skala likert) yang digunakan dalam penelitian.

Tabel 2. Skala Pengskoran

\begin{tabular}{|c|c|c|c|}
\hline Alternatif Jawaban & Kode & Skor Positif & Skor Negatif \\
\hline Sangat Setuju & SS & 4 & 1 \\
Setuju & S & 3 & 3 \\
Tidak Setuju & TS & 2 & 4 \\
Sangat Tidak Setuju & STS & 1 & 3 \\
\hline
\end{tabular}

Instrumen yang digunakan berupa angket terdiri dari pernyataan positif dan negative. Tingkat kesetujuan responden diklasifikasikan sebagai berikut; Sangat Setuju (SS), Setuju (S), Tidak Setuju (TS), dan Sangat Tidak Setuju (STS). Agar data yang diperoleh dalam penelitian berupa data kuantitatif, maka setiap butir jawaban diberi skor dalam bentuk skala Liker. Selanjutnya informasi disajikan dalam wujud tabel frekuensi serta setelah itu dilakukan pengkategorian dan menyajikan informasi dalam wujud histogram. Data dikelompokan menjadi empat kategori yaitu: Sangat Baik, Cukup Baik, Kurang Baik, dan Tidak Baik. (Sudijono, 2012) Pengkategorian dalam skala sebagai berikut.

Tabel 3. Norma Pengkategorian

\begin{tabular}{|c|c|c|}
\hline No. & Rentang & Kategori \\
\hline 1 & $\mathrm{X} \geq \mathrm{M}+15 \mathrm{SD}$ & Sangat Baik \\
\hline 2 & $\mathrm{M} \leq \mathrm{X}<\mathrm{M}-1 . \mathrm{SD}$ & Baik \\
\hline 3 & $\mathrm{M}-1 . \mathrm{SD} \leq \mathrm{X}<\mathrm{M}$ & Cukup Baik \\
\hline 4 & $\mathrm{M}-1 . \mathrm{SD}>\mathrm{X}$ & Kurang Baik \\
\hline
\end{tabular}

Keterangan.

$\mathrm{X} \quad$ : Skor yang diperoleh

SD : standar deviasi

$\mathrm{M} \quad$ : mean (rata-rata)

Data disajikan dalam bentuk frekuensi relatif yang yang dituangkan dalam bentuk angka prosentase. Untuk memperoleh persentase digunakan rumus:

Keterangan:

$\mathbf{p}=\mathbf{f} / \mathbf{N} \times 100 \%$

$\mathrm{P}$ : angka persentase

F : frekuensi

$\mathrm{N}$ : jumlah subjek/ responden

\section{HASIL DAN PEMBAHASAN}

Berdasarkan hasil penelitian yang telah diperoleh di lapangan mengenai Minat Siswa DalamMengikuti Ekstrakurikuler Futsal di SMA Negeri Se Kecamatan Cikampek, Peneliti akan mendeskripsikan dan menganalisis data tersebut menggunakan metode deskriptif dengan pendekatan kuantitatif. Untuk memperoleh data dalam penelitian ini, peneliti menggunakan instrumen survey study menggunakan angket, dengan skala pengukuran menggunakan skala likert, skala likert digunakan untuk mengukur sikap, pendapat, dan persepsi seseorang atau kelompok tentang fenomena sosial.

Adapun dalam menyusun butir-butir pertanyaan, peneliti menetapkan 2 faktor dan 8 indikator yaitu : 1) Faktor internal minat siswa dalam mengikuti ekstrakurikuler futsal, dengan 4 indikator meliputi : a) Motivasi, b)

Dipublikasikan Oleh :

UPT Publikasi dan Pengelolaan Jurnal

Universitas Islam Kalimantan Muhammad Arsyad Al-Banjari Banjarmasin 
Cita-Cita, c) Bakat, d) Hobi. Lalu 2) Faktor Eksternal minat siswa dalam mengikuti ekstrakurikuler futsal, dengan 4 indikator meliputi: a) Keluarga, b) Teman Pergaulan, c) Lingkungan, d) Fasilitas.

Dari hasil penelitian yang diperoleh, Minat Siswa Dalam Mengikuti Ekstrakurikuler Futsal di SMA negeri Se Kecamatan Cikampek dikategorikan menjadi 4 kategori yaitu, kategori sangat baik, baik, cukup baik,dan kurang baik. Sehingga statistik deskriptif mengenai minat siswa dalam mengikuti ekstrakurikuler futsal di SMA negeri se kecamatan cikampek dapat dilihat pada tabel berikut

Tabel 4. Minat Siswa Dalam Mengikuti Ekstrakurikuler Futsal di SMA Negeri se Kecamatan Cikampek

\begin{tabular}{|c|c|c|c|c|}
\hline No. & Interval & Kategori & Frekuensi & \% \\
\hline 1 & $\mathrm{x}>132.88$ & Sangat Baik & 9 & $16 \%$ \\
\hline 2 & $122.49<\mathrm{x}<132.88$ & Baik & 14 & $25 \%$ \\
\hline 3 & $112.10<\mathrm{x}<122.49$ & Kurang baik & 24 & $44 \%$ \\
\hline 4 & $\mathrm{x}<122.10$ & sangat tidak baik & 8 & $15 \%$ \\
\hline
\end{tabular}

Berdasarkan tabel tersebut dapat dijelaskan bahwa secara keseluruhan minat siswa dalam mengikuti ekstrakurikuler futsal di SMA Negeri se Kecamatan Cikampek, secara rinci terdapat 9 siswa (16\%) dalam kategori sangat baik, 14 siswa (25\%) dalam kategori baik, 24 siswa (44\%) dalam kategori kurang baik, 8 siswa $(15 \%)$ dalam kategori sangat tidak baik. frekuensi terbanyak terdapat pada kategori kurang baik, sehingga dapat disimpulkan minat siswa dalam mengikuti ekstrakurikuler futsal di SMA Negeri se Kecamatan Cikampek berkategori kurang baik. Apabila digambarkan dalam bentuk diagram batang diperoleh sebagai berikut:

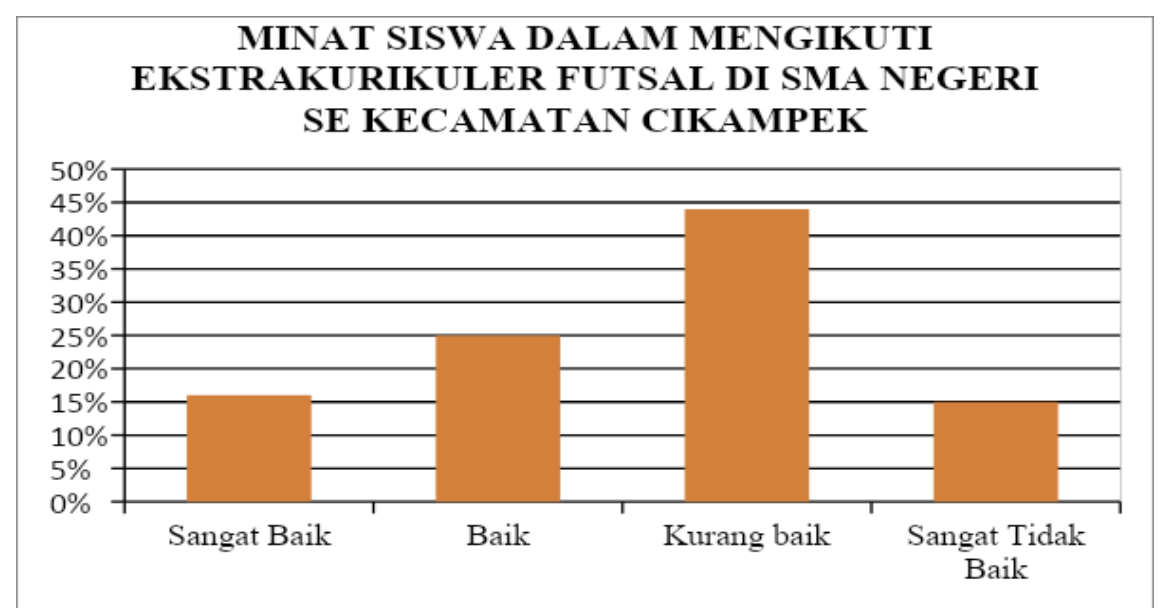

\section{Gambar 1. Diagram Batang Minat Siswa Dalam Mengikuti Ekstrakurikuler Futsal di SMA Negeri se Kecamatan Cikampek Secara Keseluruhan}

Selanjutnya, hasil penelitian secara lebih rinci akan di deskripsikan mengenai 2 faktor dan 8 deskriptor yaitu : 1) Faktor internal minat siswa dalam mengikuti ekstrakurikuler futsaldi SMA negeri se Kecamatan Cikampek yang berkategori kurang baik dengan jumlah 19 siswa (35\%), dengan 4 indikator meliputi : a) Motivasi yang berkategori kurang baik dengan jumlah 25 siswa (45\%), b) Cita-Cita yang berkategori kurang baik dengan jumlah 27 siswa (31\%), c) Bakat yang berkategori baik dengan jumlah 26 siswa (47\%), d) Hobi yang berkategori kurang baik dengan jumlah 20 siswa (36\%). 2) Faktor eksternal minat siswa dalam mengikuti ekstrakurikuler futsaldi SMA negeri se Kecamatan Cikampek yang berkategori kurang baik dengan jumlah 29 siswa (53\%), dengan 4 indikator meliputi : a) Keluarga yang berkategori kurang baik dengan jumlah 26 siswa $(47 \%)$, b) Teman pergaulan yang berkategori kurang baik dengan jumlah 27 siswa (49\%), c) Lingkungan yang berkategori sangat tidak baik dengan jumlah 44 siswa (80\%), d)Fasilitas yang berkategori kurang baik dengan jumlah 25 siswa (45\%) Sehingga dapat diketahui bahwa minat siswa dalam mengikuti ekstrakurikuler futsaldi SMA negeri se Kecamatan Cikampek masuk dalam kategori kurang baik yang artinya siswa kurang berminat dalam kegiatan ekstrakurikuler futsal yang dilakukan.

Dipublikasikan Oleh :

UPT Publikasi dan Pengelolaan Jurnal

Universitas Islam Kalimantan Muhammad Arsyad Al-Banjari Banjarmasin 


\section{PENUTUP}

Berdasarkan hasil penelitian dan pembahasan, maka dapat disimpulkan bahwa: pertama, internal minat siswa dalam mengikuti ekstrakurikuler futsal di SMA negeri se Kecamatan Cikampek secara keseluruhan adalah kurang baik. Berdasarkan hasil dari penelitian saran untuk pihak sekolah diharapkan memperhatikan minat siswa dalam melakukan ekstrakurikuler futsal, serta pelatih atau pembina dapat memberikan motivasi serta dorongan yang positif agar siswa dapat memiliki minat yang tinggi terhadap kegiatan ekstrakurikuler futsal yang dilakukan dan memberikan sarana dan prasarana atau fasilitas agar memudahkan siswa dalam mengikuti ekstrakurikuler futsal. Selanjutnya melanjutkan penelitian yang telah dibuat dengan memiliki lebih banyak keragaman dan juga lebih terperinci dengan menjadikan penelitian ini sebagai aspirasi dalam melakukan penelitian di bidang pendidikan jasmani khususnya dalam ekstrakurikuler futsal.

\section{REFERENSI}

Sudijono, A. (2012). Pengantar Statistik. Raja Grafindo Persada, Jakarta.

Sugiyono, P. D. (2013). Statistik untuk Penelitian. CV. Alvabeta Bandung.

Andriani, R., \& Rasto, R. (2019). Motivasi belajar sebagai determinan hasil belajar siswa. Jurnal Pendidikan Manajemen Perkantoran, 4(1), 80. https://doi.org/10.17509/jpm.v4i1.14958

Armi, D., Mansur, \& Nusufi, M. (2015). Partisipasi Orang Tua Terhadap Minat Anak Berolahraga di Kecamatan Singkil Kabupaten Aceh Singkil. Jurnal Ilmiah Mahasiswa Pendidikan Jasmani, Kesehatan Dan Rekreasi, Fakultas Keguruan Dan Ilmu Pendidikan Unsyiah, 4(2), 258-271. http://repositorio.unan.edu.ni/2986/1/5624.pdf

BUDIONO, T. (2013). Minat Siswa Dalam Mengikuti Ekstra Kurikuler Futsal. Jurnal Pendidikan Olahraga Dan Kesehatan, 1(1), 37-39.

Charisma Nur, \& Cahyo, D. (2017). Minat Siswa MTsN 1 Paron Ngawi Pada Kegiatan Ekstrakulikuler Bola Basket. Jurnal Pendidikan Olahraga Dan Kesehatan, 5(2), 291-296.

Dollah, A. A., Mentara, H., Iskandar, H., \& Tadulako, U. (2018). SURVEI MINAT SISWI TERHADAP OLAHRAGA FUTSAL DI SMAN 3 PALU. 0383, 22-29.

Drajat Bagus Prakoso,Hadi Setyo Subiyono, S. R. (2013). Minat Bermain Futsal Di Jenis Lapangan Vinyil, Parquette, Rumput Sintetis Dan Semen Pada Pengguna Lapangan Di Semarang. Journal of Sport Sciences and Fitness, 2(2), 14-18.

Gunawan, A. P., Achmad, I. Z., \& Resita, C. (2020). Tingkat pemahaman aktivitas renang pada siswa. $156-169$. https://doi.org/10.31571/jpo.v9i2.1899

HALIM, S. (2013). MINAT SISWA SMA Dr. SOETOMO SURABAYA PADA KEGIATAN EKSTRAKURIKULER FUTSAL. Jurnal Pendidikan Olahraga Dan Kesehatan, 1(1), 260-264.

Martaningtyas, A. (2019). MINAT DAN MOTIVASI ATLET JUNIOR DALAM MENGIKUTI LATIHAN TARUNG DERAJAT DI SATLAT SE KARESIDENAN SEMARANG TAHUN 2019.

Pramana, E. A. (2019). EKSTRAKURIKULER OLAHRAGA DI SMP NEGERI SE-KECAMATAN BATANG, KABUPATEN BATANG ”.

Rohmantunisa, S., Wahyudi, U., \& Yudasmara, D. S. (2020). Survei minat siswa dalam mengikuti kegiatan ekstrakurikuler bolabasket pada peserta sekolah menengah pertama. Sport Science and Health, 2(2), 119129. http://journal2.um.ac.id/index.php/jfik/article/view/11266/5286

Romadon, H. muhamad. (2018). Survey Minat Siswa Dalam Mengikuti Ekstrakurikuler Futsal Di Sma N 1 Kibin. Jurnal Pendidikan Olahraga Dan Kesehatan, 53(9), 1689-1699.

Dipublikasikan Oleh :

UPT Publikasi dan Pengelolaan Jurnal

Universitas Islam Kalimantan Muhammad Arsyad Al-Banjari Banjarmasin 
Safitri, F. N., \& Kustini, S. (2014). Pengaruh Minat Belajar, Kondisi Sosial Ekonomi Orang Tua, Dan Lingkungan Sekolah Terhadap Prestasi Belajar Ekonomi Pada Siswa Kelas Xi Ips Sma Negeri 4 Magelang Tahun Ajaran 2013/2014. Economic Education Analysis Journal, 3(2), 249-256.

Vinet, L., \& Zhedanov, A. (2011). MINAT SISWA TERHADAP EKSTRAKURIKULER TARI DI SMP NEGERI 34 PADANG. Journal of Physics A: Mathematical and Theoretical, 44(8), 1689-1699. https://doi.org/10.1088/1751-8113/44/8/085201

Widiyono, I. P. (2020). SURVEI POLA PEMBINAAN EKSTRAKURIKULER OLAHRAGA FUTSAL SMP NEGERI DI KABUPATEN KEBUMEN. 01(2), 8-13.

Dipublikasikan Oleh : 